\title{
O Poder de Polícia, o Desenvolvimento e a Segurança Nacional*
}

\author{
Manoel Gonçalves Ferreira Filho \\ Professor Titular de Direito do Estado da Faculdade de \\ Direito da Universidade de São Paulo.
}

\section{O termo "polícia e sua acepção genérica"}

1.1 Sempre que são muitas as acepções de um termo, importa esclarecer-lhe o significado, a fim de evitar ambigüidades ou obscuridades. $\mathrm{E}$ isto é indispensável toda vez que esse termo é determinante do assunto a ser tratado.

Ora, assim é com o termo "polícia". Hoje, na linguagem comum, somente é ele empregado para designar um dos aparelhamentos estatais. Entretanto, guarda ainda na linguagem jurídica e administrativa um outro sentido mais abrangente.

Conforme aponta José Cretella JúnioR, com a dupla autoridade de mestre da língua e de professor de Direito Administrativo:

\footnotetext{
“A palavra portuguesa policia, representada nas várias línguas românicas e anglo-germânicas, origina-se do grego politeia, através da forma latina politia, aliás dé raro emprego.

Ligada, etimologicamente, ao vocábulo política, pois ambas vêm do grego pólis (cidade, Estado), indicou entre os helênicos, a constituição do Estado, a boa constituição, o bom ordenamento" 1 .
}

1.2 Essa etimologia justifica por que, até fins do século XVIII, o termo polícia, ou seus equivalentes nas línguas irmãs, era empregado numa acepção genérica. Designava o bom andamento da coisa pública, a boa ordem da sociedade civil por que

* Conferência pronunciada na Escola Superior de Guerra em 3 de setembro de 1981.

1. José Cretella Junior, Direito Administrativo do Brasil, vol. IV - Poder de Polícia, S. Paulo: Rev. dos Tribunais, 1961, pág. 20/21. 
devia zelar a autoridade leiga. Nos clássicos, por exemplo, no Espirito das Leis de MoNTESQUIEU é esse o sentido do vocábulo police.

Ora, no tipo de Estado que prevalece até os últimos anos do século das luzes, não havia a marcada distinção e a especialização de funções depois estabelecida. Os mesmos magistrados, no zelo pela boa ordem da sociedade civil, editavam posturas e regulamentos de polícia, aplicavam-nas a casos concretos, proibindo ou permitindo a atividade dos indivíduos. E puniam os infratores dessas posturas com multas e penas corporais. Assim sendo, o bom andamento da coisa pública era o objeto geral da administração. A atuação do Estado era, toda inteira, dita de polícia.

\section{Polícia, poder de polícia e aparelho policial no Estado de Direito}

2.1 O advento do Estado contemporâneo, inspirado na origem pelo pensamento liberal e disciplinado em sua ação pelo direito, importa no reequacionamento da polícia, no sentido genérico do termo. Reequacionamento esse que leva, até, ao progressivo desuso do vocábulo nessa acepção larga, prevalecendo, hoje, como se verá adiante, outros sentidos mais restritos.

Para bem compreender essa mudança, convém recordar a base liberal que preside à gênese do Estado contemporâneo. Tal base pode ser resumida na idéia de liberdade: os homens são por natureza livres. Gozam por isso de direitos fundamentais, que são projeções dessa liberdade, que são anteriores e superiores ao Estado. Este tem, por isso, a tarefa de assegurá-los e a obrigação de reconhecê-los e respeitá-los.

Para que o Estado não os desrespeite, oprimindo, impõe-se que esteja subordinado, por inteiro, a Direito. Disto decorre a sua sujeição a uma Constituição que o organize de forma a impedir o abuso do poder. O que reclamava, segundo o pensamento político liberal, a adoção da separação de poderes.

Bem exprime essa concepção o artigo 16 da Declaração de 1789 : "Toda sociedade em que não esteja assegurada a garantia dos direitos nem estabelecida a separação de poderes não tem constituição"

2.2 A fórmula de MonTESQUIEU é assim erigida em princípio fundamental e insubstituível da organização do Estado. Seu mérito político seria o de gerar um sistema de freios e contrapesos que dificultaria, ou impossibilitaria o abuso de 
poder. Hoje, sem dúvida, não goza ela do mesmo acatamento e respeito, sofrendo como sofre inúmeras entorses, conquanto permaneça como critério básico da estruturação estatal.

Como é sabido, a separação de poderes divide o exercício do poder estatal segundo um critério funcional. Distingüindo três funções, a legislativa, a administrativa ou executiva e a judiciária, procura, especializando os órgãos do Estado no exercício de cada uma delas, separá-los, isto é torná-los reciprocamente independentes. Daí três Poderes independentes, porém harmônicos.

O bom andamento da coisa pública, a polícia no seu sentido antigo e genérico, resultaria, em face da separação de poderes, não da atividade de um dos Poderes isolados mas da atuação harmônica dos três. Entretanto, cada um para isso colaboraria segundo a sua função específica.

Aponte-se a preeminência do Legislativo, no modelo clássico do Estado de Direito, pois ele edita a lei que o Executivo aplica nos atos administrativos, que o Judiciário aplica nos processos e julgamentos.

2.3 Esta predeterminação se exprime, no plano jurídico, pelo princípio da legalidade: Ninguém será obrigado a fazer ou deixar de fazer alguma coisa senão em virtude de lei.

Este princípio tem um fundamento político. Enuncia-o a Declaração de 1789 numa fórmula clássica: “A lei é a expressão da vontade geral. Todos os cidadãos têm o direito de concorrer, pessoalmente ou através de representantes, para a sua formação" (art. 6. ${ }^{\circ}, 1^{\text {a }}$ parte) .

Mas a lei há de ter um conteúdo de justiça: "A lei não proíbe senão as ações prejudiciais à sociedade", esclarece o art. $5 .^{\circ}$ da mesma Declaração. Por isso, como nela ainda se aduz, "a liberdade consiste em poder fazer tudo aquilo que não prejudique a outrem: assim, o exercício dos direitos naturais de cada homem não tem por limites senão os que asseguram aos outros membros da sociedade o gozo dos mesmos direitos. Estes limites apenas podem ser determinados pela lei" (art. $4 .^{\circ}$ ).

Estes postulados bisseculares ainda informam o regime constitucional no mundo ocidental. Deles resulta claramente que os direitos fundamentais do homem somente devem ser disciplinados para que o seu exercício por uns não exclua 0 seu exercício por outros e sempre por meio da lei.

Em conseqüência, a "boa ordem da sociedade civil", a polícia no sentido genérico, é assegurada nos termos da lei. $\mathrm{E}$ não o pode ser fora do âmbito dessa lei, ou seja, arbitrariamente. 
2.4 Definido esse quadro legal, a sua efetivação compete ao Poder Executivo. A função deste é, com efeito, a de executar a lei.

Mas esta execução da lei comporta pelo menos três aspectos distintos.

Em muitos casos, as normas legais são demasiado gerais para que seja possível o seu cumprimento ou aplicação imediatos. Torna-se preciso, para ensejar essa observância, que sejam elas regulamentadas. Ou seja, os preceitos legais serão desdobrados em normas mais pormenorizadas que as precisam, especialmente fixando os meios, o como se deve agir. Aqui, o Executivo usa de seu poder regulamentar, que é um poder normativo subordinado ao poder legislativo, preparando a execução da lei.

Noutros, o Executivo, em face de normas legais que podem desde logo ser executadas, ou que já foram regulamentadas, edita atos que as aplicam a casos concretos. Tal se dá quando esse Poder autoriza ou proíbe que os indivíduos façam isto ou aquilo, autorização ou proibição que mediatamente se ampara na lei e em última instância na Constituição. $\mathrm{E}$, pela força se preciso, impõe essa autorização ou proibição.

Enfim, para fazer respeitar as leis, para preparar os regulamentos, para editar os atos de aplicação, o Executivo necessariamente compreende um aparelhamento administrativo, um conjunto de órgãos e de agentes devotados à execução da lei.

Relacionam-se os dois primeiros aspectos, diretamente, com o que, na terminologia do Direito Público, se denomina de poder de polícia. O último com o que, na linguagem corrente, todos chamam de polícia.

2.5 A expressão poder de polícia tem um sentido técnico no Direito Administrativo, campo em que é de largo uso. Abrange o que remanesce em mãos do Executivo do poder de zelar pela boa ordem da sociedade civil, após a partilha de funções decorrente da separação de poderes.

No Estado liberal, observe-se, quando a ele se dava tão-somente a missão de garantir a ordem, dentro da qual cada um por si buscaria o próprio bem-estar, era bem restrito o âmbito do poder de polícia. Entendia-se que ele se circunscrevia à defesa da ordem pública e da segurança. Com o Estado social, o seu campo se ampliou. Segundo já recomendava, em 1915, RUI BARBOSA, passou também a alcançar os interesses econômicos, assim a doutrina mais recente inclui no seu objetivo todas as necessidades públicas. 
Como já se sugeriu acima, de diversos modos exerce o Executivo esse poder de polícia.

Ora, o Executivo disciplina uma atividade, limitando e condicionando o exercício de um direito ou liberdade, por meio de normas gerais. É o que ocorre toda vez que ele edita os regulamentos de polícia.

Orá, em face de um caso ou solicitação concreta, ele autoriza, ou proíbe, a prática de um ato ou o exercício de uma atividade. Edita, então, ato administrativo de polícia, conforme se dá quando permite um porte de arma ou licencia uma construção, ou quando não consente numa reunião ou num comício. $\mathrm{E}$, a fim de impor o respeito a essa autorização ou proibição, pode o Executivo usar da força, praticando uma ação de polícia, com o emprego dos agentes da polícia.

Em todos os casos, porém, reitere-se e sublinhe-se, o poder de polícia se fundamenta na lei. Com efeito, a regulamentação que se estabeleça, a autorização que se conceda ou negue, tem de, em última análise, sujeitar-se ao que prescreve a lei. Assim, o poder de polícia está limitado ao âmbito circunscrito pela lei. Sempre que for além dele, importa em ilegalidade e, em decorrência disto, o seu autor arcará com a sanção para tanto prevista.

É verdade que, em muitas situações, a lei deixa ao Executivo uma escolha, uma apreciação de conveniência. Dentro desses limites, poderá ele, portanto, permitir ou proibir segundo um critério de adequação ao interesse geral. Existe, nisto, o que em Direito se denomina de discricionariedade. $\mathrm{Na}$ linguagem jurídica, ao contrário da corrente, discricionário tem um sentido bem diferente do de arbitrário. Nela, discricionário é $o$ ato que opta entre várias possibilidades, todas elas aceitas pela lei, ao passo que arbitrário é contra a lei, em desobediência à lei. Por isso, o poder de polícia jamais é arbitrário mas discricionário.

Entretanto, essa discrição administrativa não é absoluta. Segundo entende a doutrina e confirmam os tribunais, o exercício dessa discrição deve respeitar a adequação de meios a fins, a proporcionalidade entre o embaraço adveniente para o indivíduo e a vantagem dela decorrente para a comunidade. Em particular, jamais poderá, validamente, estabelecer desigualdades, tratando casos iguais de modo diferente. Violaria então o princípio de igualdade, outra das peças básicas do Estado de Direito.

Nunca se deve esquecer, ademais, que nesse Estado de Direito nenhuma lesão de direito individual pode ser subtraída 
à apreciação do Judiciário (na Constituição brasileira, art. 153, $\S 4 .^{\circ}$ ). Assim os atos do Executivo estão sempre sujeitos ao controle do Judiciário. Este, em decorrência, pode invalidar atos do Executivo no exercício do poder de polícia, que incidam em ilegalidade ou sejam abusivos. O que abrange as discriminações, as desproporcionalidades, etc.

2.6 Da boa ordem da sociedade civil, como se apontou, o Estado liberal somente considerava a seu cargo a manutenção da paz. Era ele o policial da sociedade, daí a eloqüente expressão francesa Etat-gendarme. Não é de estranhar, por isso, que sua atividade de polícia, no campo do Executivo, fosse confiada a um conjunto estruturado de órgãos, a um aparelhamento administrativo que veio a ser conhecido, como ainda o é, hoje por policia.

Polícia, neste último sentido, é assim o setor da máquina administrativa que se destina a assegurar a defesa e a segurança tanto individual quanto geral. Em especial, cabe-lhe impedir as mais graves violações à lei que são os crimes. A este aparelhamento cumpria, no Estado liberal, exercer boa parte o poder de polícia, autorizando ou proibindo atividades individuais ou coletivas. Dele escapava, é claro, a regulamentação que é constitucionalmente reservada ao Chefe do Executivo, ainda que, vez por outra, esta se insinuasse em portarias de autoridades policiais.

É certo que, com a ampliação do âmbito próprio ao poder de polícia resultante do Estado social, os novos campos não foram sujeitos ao aparelhamento policial e sim a outros setores da administração. Mas, no que tange à defesa e segurança, é ainda a polícia que zela pela boa ordem da sociedade civil.

Entretanto, por motivos de conveniência e economia, esse aparelhamento do executivo que é a polícia não ficou apenas com a tarefa preventiva, recebeu também a repressiva, de por fim a ações criminosas, apurando autoria e fornecendo subsídios para a punição pela Justiça dos culpados. Isto importa em dizer que entre as atribuições da polícia (aparelhamento administrativo) estão além das funções de polícia preventiva, ou administrativa, as de polícia judiciária, ou repressiva.

Saliente-se que, se nas atribuições de polícia dita preventiva se incluem faculdades inerentes ao poder de polícia do Executivo, as atribuições de polícia judiciária são estritamente as editadas pela legislação própria, em última instância pelo Código de Processo Penal.

2.7 Decorre assim nítida a distinção entre poder de polícia, e poder, ou poderes, da polícia. Estes são as atribuições 
que a lei defere ao setor da administração que é a polícia. Nelas apenas se inscreve uma fração das faculdades que, no Estado contemporâneo, abrange o poder de polícia, atribuído genericamente ao Executivo.

Enfim, em termos jurídicos, poder de polícia é, para CRETELla JÚNIOR, "faculdade discricionária do poder público de limitar a liberdade individual em prol do interesse coletivo" enquanto polícia é o aparelhamento administrativo que, pela coerção se preciso for, atua para garantir a ordem e a segurança, exercendo eventualmente mas nem sempre poder de polícia ${ }^{2}$.

\section{Poder de polícia e polícia no sistema constitucional brasileiro em vigor}

3.1 A forma do Estado brasileiro é, como ninguém ignora, a federativa. Isto importa, entre outros aspectos, na coexistência de uma ordem jurídica e de uma organização política e administrativa de caráter nacional que recobre todo o território e atinge a todos os brasileiros, com várias outras que cobrem apenas parcelas delimitadas desse território nacional e não sujeitam senão os que nele se radicam. A coexistência, pois, da ordem da União com as ordens estaduais, os Estados.

Entretanto, é peculiaridade do Estado brasileiro a existência de uma terceira ordem que, fundada embora na Constituição federal, se inscreve em dimensões territoriais e pessoais ainda menores, aparecendo como descentralizações das ordens estaduais. São as ordens municipais, os Municípios.

Esta coexistência da União, dos Estados e dos Municípios presume, não só mas forçosamente, uma repartição de competências. Não poderia haver separação entre elas se as suas atribuições não fossem distintas; haveria completa barafunda política e administrativa se essas funções fossem confundidas.

No direito brasileiro, a regra fundamental de divisão de competências estabelece que pertencem à União, de um lado, aos Municípios, de outro, as competências que a Constituição federal explícita ou implicitamente lhes atribui. O remanescente compete aos Estados (art. 13, 1. ${ }^{\circ}$ : "Aos Estados são conferidos todos os poderes que, explícita ou implicitamente, não lhes sejam vedados").

2. Inem, Dicionário de Direito Administrativo, Rio de Janeiro, Forense, $3 .^{\text {a }}$ ed., 1978, voce "poder de polícia" 
Esta regra, inspirada na Constituição americana, é adotada em nosso Direito desde a Constituição de 1891. Entretanto, o processo de centralização, acentuado mormente depois da Revolução, levou a grande alargamento do âmbito da competência da União, como se comprova da simples leitura do art. $8 .^{\circ} \mathrm{da}$ Constituição vigente que enuncia as suas competências exclusivas. Por outra parte, houve também, em menor escala, um fortalecimento do Município. Tudo isto reduz muito, como é óbvio, a competência remanescente, própria dos Estados.

3.2 Todas essas três ordens, União, Estados e Municípios, contam com poder de polícia. A repartição de competências entre eles divide a faculdade de limitar a liberdade individual em vista do interesse geral.

E de se observar que, no campo reconhecido pelo liberalismo, defesa da ordem, segurança pública, o poder de polícia pertence basicamente aos Estados. A estes, por exemplo, é dado regulamentar e autorizar ou proibir reuniões públicas, comícios, passeatas, ainda que nas lindes de lei federal que desdobra direitos fundamentais reconhecidos na Constituição.

No campo novo dos interesses econômicos, é a União que o exerce principalmente. Cuida ela de regulamentar e controlar atividades financeiras, por exemplo, para impedir dano à economia.

O campo do Município abrange, nos termos da Constituição (art. 15, II), a esfera de seu "peculiar interesse". O que, na opinião dos intérpretes, significa a esfera em que preponderam interesses locais, como o que toca a utilização da propriedade para edificações, etc.

3.3 Igualmente, União e Estados contam com polícia.

A manutenção da ordem interna, - repita-se - quer no seu aspecto preventivo, quer no repressivo, compete em primeira linha aos Estados. Igualmente a apuração dos delitos. Assim, em princípio, as medidas e ações relativas a essa tarefa cabem ao aparelhamento policial que os Estados necessariamente hão de constituir e sua efetivação aos agentes integrados nessa máquina.

Note-se que, a tal ponto a Constituição encarece a missão estadual de combater as perturbações da ordem que o seu insucesso é uma das causas de intervenção federal (art. 10, III). É verdade que, mesmo sem intervenção federal mas aí em consonância com o Poder estadual, as Forças Armadas podem ser empregadas para por cobro a desordens e conflitos. De fato, o art. 91 da Constituição não as destina apenas "à defesa 
da Pátria" mas também "à garantia dos poderes constituídos, da lei e da ordem" que as perturbações contestam.

A polícia estadual desempenha, em conseqüência, atribuições de polícia administrativa, ou preventiva, e de polícia judiciária, ou repressiva.

Desdobra-se em dois braços, um civil e outro militar. Este último, o único a que faz referência a Constituição federal (art. 13, § $4 .^{\circ}$ ) que lhes dá por finalidade a manutenção da ordem pública e lhes inscreve como "forças auxiliares, reserva do Exército". Ao primeiro compete a atividade de polícia judiciária e não poucas de caráter preventivo.

3.4 A Constituição brasileira atribui à União uma esfera determinada tanto de polícia administrativa como de polícia judiciária. Resulta do art. $80^{\circ}$, VIII do texto vigente que a União tem de organizar um aparelhamento policial, a Polícia Federal, à qual se deferem "os serviços de polícia, marítima, aérea e de fronteiras", a prevenção e a repressão do "tráfico de entorpecentes e drogas afins", a apuração de "infrações penais contra a segurança nacional, a ordem política e social ou em detrimento de bens, serviços ou interesses da União, assim como outras infrações cuja prática tenha repercussão interestadual e exija repressão uniforme, segundo se dispuser em lei", e a "censura de diversões públicas".

Admite a Constituição, todavia, que, por meio de convênio, essa atuação seja delegada ou transferida ao aparelhamento estadual (art. 13, $\S 3 .^{\circ}$ ), como ocorre em alguns casos, presentemente.

3.5 Quanto aos Municípios, não se lhes reconhece o poder de constituir um aparelhamento policial. A Constituição paulista, para citar um exemplo, permite-lhes, todavia, "organizar e manter guardas municipais para colaboração na segurança pública, subordinadas à Polícia estadual".

Hely Lopes MeIrelles, no livro Direito Municipal Brasileiro, aponta que essa guarda municipal se destina "ao policiamento administrativo da cidade, especialmente dos parques e jardins, dos edifícios públicos e museus, onde a ação dos predadores do patrimônio público se mostra mais danosa" ${ }^{3}$. Registra, porém, que isto leva freqüentemente a um conflito de atribuições com a polícia militar estadual. Afirma ele que "a guarda municipal; ou que nome tenha, é apenas um corpo de

3. Hely Lopes Meirelles, Direito Municipal Brasileiro, São Paulo: Rev. dos Tribunais, 3.a ed., 1977, pág. 516/517. 
vigilantes adestrados e armados para a proteção do patrimônio público e maior segurança dos munícipes, sem qualquer incumbência de manutenção de ordem pública (atribuição da polícia militar) ou de polícia judiciária (atribuição da polícia civil). Opinião que, aliás, não se coaduna exatamente com o preceito da Constituição estadual.

O que parece indiscutível é que o Município pode ter guardas para a segurança de seus próprios, o que, nos termos da lei, não se recusa a empresas ou até a particulares.

\section{O poder de polícia e o desenvolvimento}

4.1 Cabe agora salientar pontos e linhas em que o poder de polícia, quer da União, quer dos Estados e até dos Municípios, tem impacto sobre o desenvolvimento.

Note-se que o poder de polícia tem sempre uma conotação negativa. É limitação de liberdades. Freio, portanto, nunca acelerador. $O$ poder de polícia jamais instiga o desenvolvimento, disciplina atividades que levam a ele, servindo para mantê-las na direção do interesse geral. Não o promove nunca. O Estado contemporâneo, é certo, cuida de promover o desenvolvimento mas usa então de estímulos, empreende ações que de modo algum se enquadram no conceito restrito de poder de polícia. Seriam, sem dúvida, de polícia, no sentido antigo e geral do termo, pois evidentemente conduzem à boa ordem da sociedade civil.

No campo do desenvolvimento, manifesta é a repercussão do poder de polícia na medida em que incide sobre a liberdade de iniciativa, em especial.

4.2 Não é baldado insistir no fato de que a Constituição brasileira põe como um dos princípios da ordem econômica a liberdade de iniciativa (art. 160, I). Mais. Defere, em princípio, à iniciativa privada as atividades econômicas. Com efeito, segundo está no art. 170, caput: "Às empresas privadas compete, preferencialmente, com o estímulo e o apoio do Estado, organizar e explorar as atividades econômicas".

Essa liberdade de iniciativa que se traduz na liberdade de empresa, nada mais é, porém, do que uma das feições da liberdade de trabalho, ofício, profissão que conflui com a de indústria ou comércio inscritas nas Declarações de Direitos desde a época liberal. No Brasil, desde a Carta de 1824. De fato, essa liberdade, no fundo, é o direito de exercer atividade socialmente útil. Atividade essa que obviamente pode exercitar-se nos mais variados setores. 
Tal liberdade de exercer atividades socialmente úteis necessariamente há de ser limitada, a fim de que não resultem prejuízos para o bem comum. Segundo está na Constituição, está ela sujeita desde logo a "condições de capacidade" que a lei há de fixar (art. 153, § 23). E, quando voltada para o domínio estritamente econômico, essa liberdade de empresa pode ser excluída, pela lei, em relação a atividades concernentes à segurança nacional ou em setores que não possam ser desenvolvidos "com eficácia no regime de competição" (art. 163).

A legislação limitadora dessa liberdade é federal nalguns aspectos. Assim, é a lei federal que pode estabelecer as condições de capacidade relativamente às profissões liberais e técnico-científicas (art. 8., XVII, $r$ ), produção e comércio de material bélico (art. $8^{\circ}$, VII), comércio exterior e interestadual (art. 8..$^{\circ}$ XVII, 1) etc., bem como somente ela pode instituir os monopólios decorrentes das necessidades da segurança nacional ou da ineficácia setorial da iniciativa privada (art. 163).

Não falta, porém, aos Estados competência para legislar em matéria de produção e consumo, por exemplo, o que interfere na liberdade de empresa. É o que decorre do art. $8 .^{\circ}$, parágrafo único, que atribui essa matéria à competência concorrente da União e dos Estados.

Enfim, no tocante a seu peculiar interesse, mormente no que concerne à localização de atividades comerciais ou industriais, incide a competência municipal.

Resulta disto, sempre, o poder de polícia da União, dos Estados e dos Municípios, em caráter exclusivo ou concorrente, conforme o caso. Isto seja para regulamentar a legislação pertinente, seja para, com base nela, permitir ou proibir as atividades, efetivando pela coerção, se preciso, as suas decisões.

Merece menção neste ponto o poder de polícia decorrente para a União da Lei Delegada $n .^{\circ} 5$, de 26 de setembro de 1962. Esta lei de intervenção no domínio econốmico atribui à União, e exclusivamente a ela, o poder de tabelar preços relativamente a preços de bens e serviços essenciais ao consumo e uso do povo.

\section{O poder de polícia e a segurança}

5.1 O terreno de eleição do poder de polícia é o da segurança. Isto se assenta no pensamento liberal e não resulta abandonado em conseqüência da evolução posterior. Ao con- 
trário, no Estado social, mais ainda se tem aprofundado a limitação das liberdades e direitos fundamentais, com o alargamento do poder de polícia.

5.2 Nem a liberdade pessoal escapa ao poder de polícia. 0 aspecto externo desta, a liberdade de locomoção, sofre cerceamentos visando à manutenção da ordem pública e à própria segurança individual.

Isto é flagrante quando se considera a polícia do trânsito e tráfego. De fato, variadas limitações e mesmo proibições podem nesse campo ser impostas, cerceando a liberdade de ir e vir, mas salvaguardando o interesse geral.

Note-se que, embora a legislação nessa matéria compita à União (art. 8. ${ }^{\circ}, \mathrm{XVII}, \mathrm{n}$ ), admitindo-se que os Estados a suplementem (art. 8. ${ }^{\circ}$, parágrafo único), o poder de polícia também se estende aos Municípios. Estes, sempre levando em conta o preponderante interesse local, podem dispor sobre a circulação de veículos e até de pedestres.

5.3 A liberdade de expressão do pensamento não refoge por completo ao poder de polícia.

A matéria é delicada, por isso convém reproduzir o texto constitucional (art. 153, $\S 8^{\circ}$ ) : "É livre a manifestação do pensamento, de convicção política ou filosófica, bem como a prestação de informação, independentemente de censura, salvo quanto a diversões ou espetáculos públicos, respondendo cada um, nos termos da lei, pelos abusos que cometer. o direito de resposta. A publicação de livros, jornais e periódicos não depende de licença da autoridade. Não serão, porém, toleradas a propaganda de guerra, de subversão da ordem ou de preconceitos de religião, de raça ou de classe, e as publicações e exteriorizações contrárias à moral e aos bons costumes"

Resulta desse texto, a par do princípio de liberdade, a censura, portanto, o poder de polícia, relativamente a diversões ou espetáculos públicos. Poder esse pertencente à União como o comprova o art. 8, VIII, d, referente à competência da Polícia Federal.

Se esse primeiro ponto é incontestável, é ainda hoje controvertido o alcance da parte final do art. $153, \S 8 .^{\circ}$, ou seja, da determinação que não sejam toleradas a propaganda de guerra, de preconceitos de raça e as publicações e exteriorizações contrárias à moral e aos bons costumes etc. O Governo Médici entendeu que isto impunha ao Executivo o dever de impedir que viessem a público essas manifestações intoleráveis. Editou, por isso, o Decreto-lei n. ${ }^{\circ} 1.077$, de 1970 , que instituía uma 
"verificação prévia" e, em conseqüência, estabelecia o poder de polícia necessário para impedir, sendo o caso, a divulgação dessas manifestações. Contra isso, insurgiu-se ponderável corrente, para a qual essa intolerabilidade não excluiria a livre manifestação, simplesmente imporia ao legislador a previsão de ilícitos penais que a sancionassem. Isto porque, e sobretudo, a "verificação prévia" seria uma forma de censura.

$5.4 \mathrm{O}$ poder de polícia, acrescente-se, pende, de modo incontroverso, sobre outros aspectos dos chamados "bons costumes". Com efeito, esse poder, sempre motivado pelo intento de preservair a boa ordem da sociedade civil, sempre teve de restringir a liberdade, para preservar o interesse geral em que certos males não se difundam. Assim, no tocante ao jogo, ao alcoolismo, à prostituição.

No âmbito da lei, o poder público, mormente por intermédio da polícia estadual, tem regulamentado a instalação de casas de jogos lícitos, de estabelecimentos que vendam bebidas alcoólicas. $\mathrm{E}$ até, em termos não raro contestáveis, a de casas de tolerância, inclusive chegando a estabelecer as "zonas de meretrício".

5.5 Também é incontroverso $o$ poder de polícia que se exerce em defesa da saúde pública. Na verdade, foi esse o primeiro campo que os juristas liberais acrescentaram ao tradicional, isto é, a defesa e a segurança.

A base legal da proteção à saúde é traçada em normas gerais que são da competência da União (art. $8 .^{\circ}$, XVII, c) como o é a de estabelecer plano nacional de saúde (item XIV). Cabe, todavia, legislação complementar estadual (art. 8. parágrafo único). Disto decorre poder de polícia para a União e evidentemente para os Estados, mas disso não resulta a exclusão do Município de qualquer atuação nesse campo. Tome-se, por exemplo, a questão da poluição e logo se verá que, embora caiba aos Estados o esforço principal, será esse problema insolúvel sem a cooperação da União e dos Municípios.

$\mathrm{O}$ poder de polícia em matéria de saúde se reflete principalmente no controle sobre medicamentos, alimentos, na profilaxia e combate de epidemias, graves moléstias contagiosas e epizotias, afora a já mencionada poluição.

5.6 Terreno novo do poder de polícia é a ecologia. Cabe, com fundamento nele, tomar medidas de preservação do meio ambiente. $E$ estadual a competência a este respeito, entretanto, tal qual se viu acima em relação à saúde, a União e os Municípios têm também esfera onde exercê-lo. 
5.7 Já terreno antigo desse poder é de uso da propriedade imobiliária. Aqui avulta a disciplina da ocupação do solo, que por sua natureza cai no âmbito do peculiar interesse local e conseqüentemente no de sua competência. No âmbito da legislação sobre zoneamento, construções etc., resta vasto espaço para limitações, proibições, permissões decorrentes do poder de polícia.

5.8 Enfim, convém réferir em virtude de seu reflexo político a incidência do poder de polícia sobre a liberdade de reunião. Reconhece-o a Constituição no art. 153, § 27: “Todos podem reunir-se sem armas, não intervindo a autoridade senão para manter a ordem. A lei poderá determinar os casos em que será necessária a comunicação prévia à autoridade bem como a designação, por esta, do local da reunião".

Na esfera traçada pela lei regulamentadora (Lei Federal n. ${ }^{\circ} 1.207$, de 1950), a autoridade policial deve estabelecer, ao começo de cada ano, os logradouros públicos onde são possíveis as reuniões que são os comícios.

Ainda que para certos intérpretes mais liberais, a Constituição não permita mais do que a determinação de locais vedados para reuniões, jamais aceitando a sua proibição pura e simples, ainda que fundada em motivos de segurança, a jurisprudência tem admitido o contrário. Com efeito, tem aceitado como boa a proibição quando as circunstâncias especiais do momento as tornem perigosas para a ordem pública.

5.9 Convém observar que o quadro acima traçado que circunscreve o poder de polícia em relação às liberdades públicas, somente prevalece em situações normais. De fato, em circunstâncias anormais, ao ensejo das medidas de emergência, do estado de sítio e do estado de emergência, por força da própria Constituição, o poder de polícia se amplia.

É próprio do Estado de Direito não só dispor para a normalidade como também impor uma disciplina jurídica para circunstâncias anormais. Com isto, procura impedir o arbítrio mesmo no combate às mais graves perturbações da ordem. Em decorrência disto, as constituições estabelecem medidas extraordinárias que, por assim dizer, legalizam as próprias situações anormais previsíveis. $\mathrm{E}$ ao fazê-lo, se limitam ainda as ações de repressão, estendem sempre o campo do poder de polícia.

A Constituição vigente, por força da Emenda Constitucional n. ${ }^{\circ} 11$, de 13 de outubro de 1978 , mantém como sistema básico para a resposta a emergências graves o estado de sítio, que é da tradição de nosso direito, mas a ele acrescenta o estado de emergência e prevê medidas de emergência. 
5.10 O sistema básico é, sem dúvida, o estado de sítio, regido pelo art. 156: "No caso de guerra ou a fim de preservar a integridade e a independência do País, o livre funcionamento dos Poderes e de suas instituições, quando gravemente ameaçados ou atingidos por fatores de subversão, o Presidente da República poderá decretar o estado de sítio"

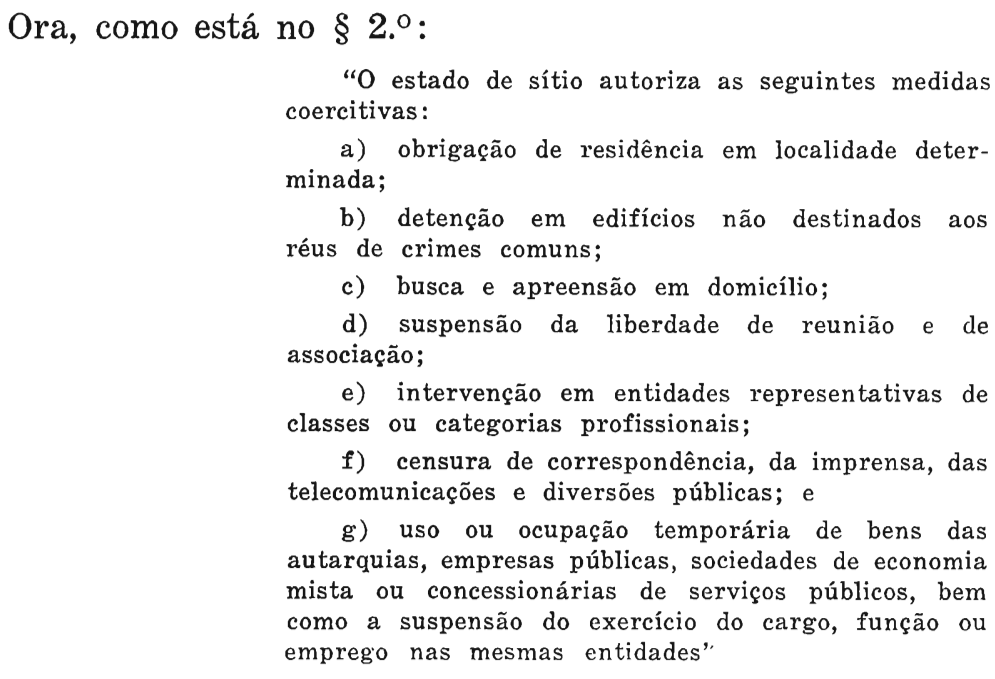

Como se vê, realmente o estado de sítio amplia o poder de polícia em relação à liberdade pessoal (alíneas $a, b)$ à de domicílio (c), reunião e associação (d), pensamento (f) etc.

Aponte-se que, mediante lei, o Congresso Nacional poderá ampliar as medidas de resposta que enseja o estado de sítio, suspendendo outras das garantias constitucionais e conseqüentemente ampliando o poder de polícia em relação a outras liberdades. Isto por um prazo máximo de cento e oitenta dias, salvo guerra quando poderá sê-lo por tempo indeterminado. $\mathrm{O}$ sítio exige, sublinhe-se, a posterior aprovação do Congresso.

5.11 Essas medidas enumeradas no art. $156, \S 2 .^{\circ}$, podem ser tomadas, como medidas de emergência, pelo "Presidente da República, para preservar ou, prontamente, restabelecer, em locais determinados e restritos a ordem pública ou a paz social, ameaçadas ou atingidas por calamidades ou graves perturbações que não justifiquem a decretação dos estados de sítio ou de emergência" Isto por um prazo máximo de sessenta dias, prorrogável por uma única vez, dando dessa decisão meramente ciência ao Congresso Nacional. É o que está no art. 155. 
5.12 Por sua vez, são essas medidas as únicas que ensejam o estado de emergência, segundo resulta do art. 158, § 2. ${ }^{\circ}$. Este estado de emergência é decretado pelo. Presidente da República, ouvido o Conselho Constitucional, "quando forem exigidas providências imediatas, em caso de guerra, bem como para impedir ou repelir as atividades subversivas" (art. 158). Tem prazo máximo de noventa dias, somente podendo ser prorrogado uma vez. Não está sujeito à apreciação do Congresso Nacional, ao qual será apenas comunicado (art. 158, § $3 .^{\circ}$ ). 